\title{
Peramalan Beban pada Gardu Induk Mantingan dalam Penentuan Kapasitas Transformator dengan Metode Regresi Linear
}

\author{
Jimmy Trio Putra $^{1 *}$, Nisaun Fadhilah ${ }^{2}$, Muhammad Arrofiq ${ }^{3}$ \\ Departemen Teknik Elektro dan Informatika, Sekolah Vokasi, Universitas Gadjah Mada \\ Gedung Herman Yohanes Sekip Unit III, Catur Tunggal, Depok, Sleman, Yogyakarta, 55281, Indonesia \\ ${ }_{1 j}$ immytrioputra@ugm.ac.id \\ 2 nisaun.fadhilah@mail.ugm.ac.id \\ ${ }^{3}$ rofigeugm.ac.id
}

Intisari - Pertumbuhan beban kelistrikan di wilayah Ngawi dan Magetan meningkat seiring rencana pemerintah dalam membangun beberapa infrastruktur dan kawasan industri. Penyedia kelistrikan harus mampu memprediksi kemampuan sistem dalam melayani konsumen. Perencanan pembangunan Gardu Induk (GI) memiliki tujuan dalam memastikan persebaran semua beban listrik yang dilayani dapat diakomodasi dengan baik. Penelitian ini menggunakan data historis dalam memprediksi besarnya permintaan kelistrikan di area GI Mantingan tahun 2019 hingga tahun 2026. Metode yang digunakan adalah metode regresi linear dengan perencanaan satu tahap, yaitu periode 8 tahun (jangka panjang). Hasil penelitian merekomendasikan bahwa sistem yang beroperasi saat ini membutuhkan persebaran beban listrik dengan memindahkan tiga penyulang di GI Magetan dan GI Ngawi ke GI Mantingan. Tiga penyulang tersebut yaitu penyulang Walikukun dan Trinil yang mendapatkan sumber dari GI Ngawi dan penyulang Sine yang mendapat sumber dari GI Magetan. Area calon pembangunan GI Mantingan yaitu didaerah Widodaren, Mantingan, Karanganyar, Ngrambe dan Sine. Penelitian menunjukan bahwa GI baru dibangun dengan kapasitas 60 MVA dan besar nilai pembebanan trafo Gardu Induk Mantingan selama 8 tahun memiliki rata-rata sebesar 41,41\% serta biaya pokok penyediaan listik (BPP) rata-rata sebesar Rp. 2.101 .

Kata kunci — kapasitas trafo, konsumsi energi listrik, regresi linear.

Abstract - The growth of electricity load in Ngawi and Magetan areas has increased due to the government's plan to build several infrastructure and industrial areas. The electricity provider must be able to predict the system's ability to serve consumers. The planning for the construction of substations (GI) is carried out to ensure that all electricity loads served can be properly accommodated. This research uses historical data in predicting the amount of electricity demand in the Mantingan substation area from 2019 to 2026. The method used is a linear regression with one-stage planning, which is for 8 years (long term). The results recommend that the current operating system requires an electric load by moving three feeders in Magetan substation and Ngawi substation to Mantingan substation. The three feeders, namely the Walikukun and Trinil feeders, were sourced from the Ngawi substation and the Sine feeders which were sourced from the Magetan substation. The prospective areas for the construction of the Mantingan Substation are Widodaren, Mantingan, Karanganyar, Ngrambe, and Sine areas. Research shows that a newly built substation with a capacity of $60 \mathrm{MVA}$ and the load value of the Mantingan substation transformer for 8 years has an average of $41.41 \%$ and an average of biaya pokok penyedia listrik (BPP) of Rp. 2,101.

Keywords - transformer capacity, electrical energy consumption, linear regression.

\section{PENDAHULUAN}

Di zaman modern ini, sumber daya energi listrik memegang peran penting dalam kemajuan peradaban manusia. Penggunaan energi listrik berkembang sebanding dengan bertumbuhnya populasi manusia, kebutuhan industri, kemajuan teknologi. Penyedia kelistrikan tidak hanya memperhitungkan terkait kuantitas kelistrikan tetapi juga mempertimbangkan terhadap kualitas dari kelistrikan; termasuk di dalamnya diperlukan keandalan yang tinggi untuk menjamin pelayanan terhadap konsumen. 
Sistem tenaga listrik (STL) yang ideal adalah sistem yang handal dan sistem yang mampu menghasilkan listrik dengan kualitas yang tinggi, namun dengan biaya produksi yang minimum. Untuk mencapai kondisi tersebut, operasi dan perencanaan STL harus dilakukan dengan baik. Operasi STL adalah proses menjalankan sistem yang ada agar dapat melayani beban dengan optimal. Sedangkan perencanaan STL adalah proses untuk membangun sistem yang baru atau menaikkan besarnya kemampuan sistem yang telah ada sehingga dapat menyeimbangi besarnya tuntutan kenaikan beban di masa depan [1].

Perencanaan STL harus dilakukan dengan tepat, karena proses pembangunan atau pengembangan infrastruktur sistem tenaga listrik membutuhkan waktu yang lama dan membutuhkan biaya investasi yang besar. Ketika perencanaan tidak dilakukan dengan tepat, maka biaya investasi dan operasi yang dikeluarkan menjadi lebih besar, serta sistem tidak akan mampu melayani pertumbuhan beban.

Salah satu perencanaan sistem tenaga listrik adalah perencanaan pengembangan Gardu Induk (GI). Perencanaan pengembangan GI merupakan salah satu langkah antisipasi pertumbuhan beban, terhadap kapasitas GI yang ada di sebuah daerah untuk periode waktu tertentu.

Ngawi dan Magetan merupakan salah satu kabupaten yang akan mengalami pertumbuhan beban terbesar di Provinsi Jawa Timur. Hal tersebut disebabkan oleh adanya beberapa infrastruktur baru yang akan dibangun sesuai dengan rencana pemerintah dan kawasan industri yang akan dibangun di Kabupaten Ngawi dan Magetan.

Berdasarkan hasil peramalan beban, kapasitas GI Ngawi dan GI Magetan saat ini tidak mampu untuk melayani pertumbuhan beban yang berupa infrastruktur baru tersebut. Oleh sebab itu perencanaan pengembangan GI perlu dilakukan.

Perencanaan pengembangan GI bertujuan untuk menentukan jenis pengembangan yang akan dilakukan, dengan cara memperbesar kapasitas GI yang sudah ada, atau membangun GI baru di lokasi yang baru. Selain itu, perencanan pengembangan GI juga bertujuan untuk menentukan kapasitas GI yang harus dibangun, agar mampu melayani pertumbuhan beban selama 8 tahun kedepan (perencanaan pengembangan GI jangka panjang).

Terdapat banyak sekali metode yang telah digunakan dalam perencanaan pembangunan gardu induk seperti penggunaan integer programminng [2], dynamic programming algorithm [3], sedangkan dengan metode metaheuristic seperti; genetic algorithm (GA) simulated annealing, dan tabu search [4]. Beberapa penelitian dalam mencari lokasi pembangunan gardu induk meyelesaikan permasalahan bersifat diskrit [6,7]. Tahun 2007 ditemukan sebuah metode metaheuristic yaitu Imperialist Competitive Algorithm (ICA).

Penelitian ini memperkenalkan metode regresi linier dalam meramalkan besarnya kebutuhan beban listrik di masa yang akan datang dengan menganalisis data yang telah ada pada tahun 2018 sehingga dapat ditentukan besarnya kapasitas gardu induk yang dibutuhkan dalam melayani beban. Data yang telah ada dapat dikumpulkan untuk mengenali suatu pola sehingga dari pola tersebut dapat diimplementasikan dalam memprediksikan besarnya pertumbuhan beban dengan menggunakan model matematis. Selain itu, dapat diprediksikan terkait dengan biaya pokok penyedia listrik dan skema persebaran pembebanan transformator sehingga dapat disesuaikan dengan kebutuhan beban.

\section{METODE PENELITIAN \\ A. Metode Regresi Linear}

Metode regresi merupakan metode penentuan sebab dan akibat antar variabel satu dengan variabel yang lain dan membentuk hubungan yang linier. Dimana, perubahan pada variabel $x$ akan mempengaruhi juga pada variabel y sehingga nanti menghasilkan dalam bentuk numerik.

Regresi linear sederhana memiliki model persamaan (1):

dimana:

$$
y=a+b x
$$

$\mathrm{y}=$ variabel akibat (dependent)

$\mathrm{x}=$ variabel penyebab (independent) 
$\mathrm{a}=$ konstanta

$\mathrm{b}=$ besaran response yang ditimbulkan oleh predictor

Variabel penyebab yang digunakan adalah periode bulan $(x)$ yang akan diprediksi dan variabel akibat adalah beban puncak 3 penyulang $(y)$. Sedangkan untuk nilai konstanta $(a)$ dan koefisien regresi $(b)$ dapat menggunakan persamaan:

$$
\begin{aligned}
& a=\frac{\left(\sum y\right)\left(\sum x^{2}\right)-\left(\sum x\right)\left(\sum x y\right)}{n\left(\sum x^{2}\right)-\left(\sum x\right)^{2}} \\
& \mathrm{~b}=\frac{n\left(\sum x y\right)-\left(\sum x\right)\left(\sum y\right)}{n\left(\sum x^{2}\right)-\left(\sum x\right)^{2}}
\end{aligned}
$$

\section{B. Gardu Induk Mantingan}

Gardu Induk mantingan merupakan Gardu Induk baru yang akan mulai dibangun dibawah naungan kerja PLN Jawa Timur. Area pelayanan GI ini mencakup 5 kecamatan yaitu Kecamatan Mantingan, Karanganyar, Widodaren dan Sine. 5 kecamatan ini terletak di bagian barat Provinsi Jawa Timur, seperti yang terlihat pada gambar 1. Kelima kecamatan ini memiliki total luas area $444 \mathrm{~km}^{2}$. Berdasarkan data yang telah diperoleh kepadatan penduduk pada 5 kecamatan ini yaitu $612,4 \mathrm{Jiwa} / \mathrm{km}^{2}$.

dimana:

$n=$ jumlah data

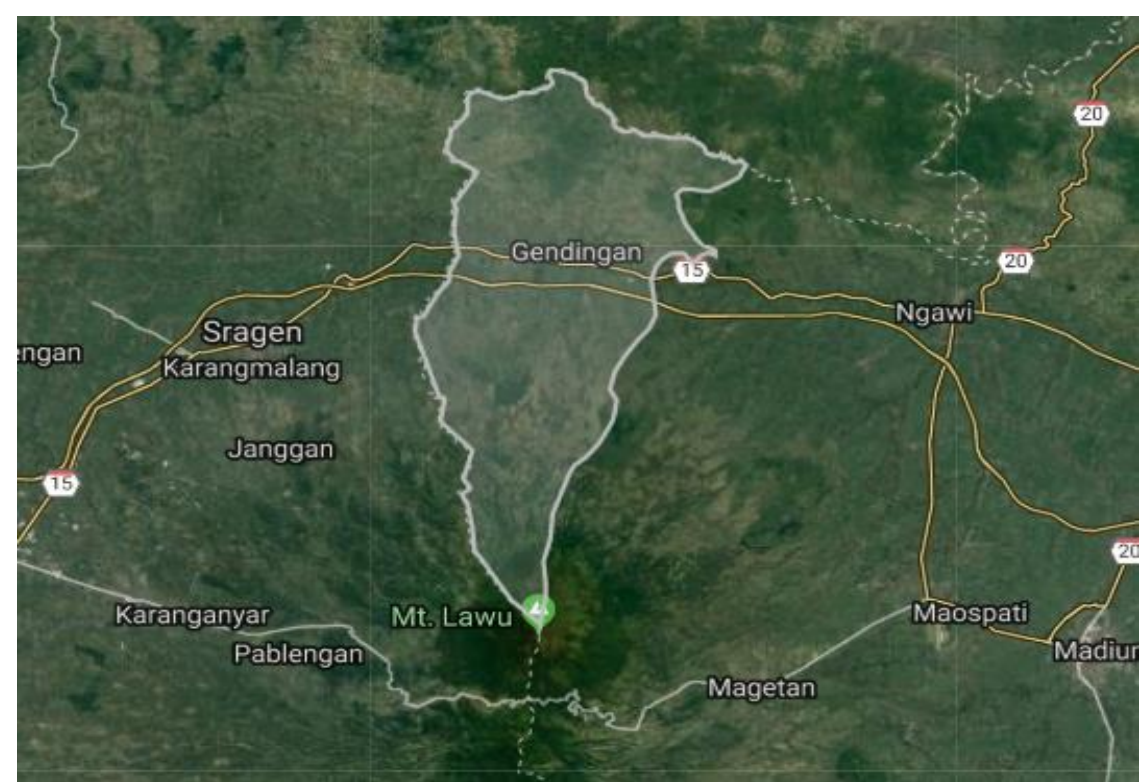

Gbr 1. Posisi Kecamatan Karanganyar, Kecamtan Widodaren, Kecamatan Ngrambe, Kecamatan Sine dan Kecamatan Mantingan

GI ini akan menerima 3 penyulang dari GI Ngawi dan GI Magetan, yaitu penyulang Sine yang berasal dari GI Magetan dan penyulang Trinil dan Walikukun yang berasal dari GI Ngawi.

\section{Transformator Daya}

Dalam penelitian ini transformator daya GI digunakan untuk menurunkan tegangan dari $150 \mathrm{kV}$ menjadi $20 \mathrm{kV}$. Trafo daya merupakan komponen yang menyumbang rugi-rugi aktif terbesar. Besar rugi-rugi tersebut pada umumnya telah dihitung oleh pabrikan dan nilainya berbeda sesuai dengan pabrikannya. Adapun besar rugi-rugi daya pada trafo daya untuk beberapa rating daya dapat dilihat pada Tabel 1 [6].

Tabel 1. Rugi-Rugi Transformator Daya

\begin{tabular}{|c|c|c|c|c|}
\hline \multicolumn{1}{|c|}{ No } & $\begin{array}{c}\text { Daya } \\
\text { Trafo } \\
\text { (MVA) }\end{array}$ & Pabrikan & $\begin{array}{c}\text { Rugi- } \\
\text { rugi } \\
\text { tanpa } \\
\text { Beban } \\
\text { (kW) }\end{array}$ & $\begin{array}{c}\text { Rugi- } \\
\text { rugi } \\
\text { dengan } \\
\text { adanya } \\
\text { beban }\end{array}$ \\
\hline 1 & 16 & $\begin{array}{c}\text { Power } \\
\text { Engineering }\end{array}$ & 8,85 & 84 \\
\hline 2 & 30 & $\begin{array}{c}\text { Power } \\
\text { Engineering }\end{array}$ & 22 & 150 \\
\hline 3 & 60 & Minera & 66,97 & 303 \\
\hline
\end{tabular}


Transformator daya memiliki kemampuan pelayanan atau nilai rating. Besar beban yang dilayani oleh trafo seharusnya tidak melebih nilai rating-nya. Pembebanan yang dialami oleh sebuah trafo daya dapat dicari dengan menggunakan faktor penggunaan, yaitu seperti pada persamaan:

dengan :

$$
U f=\frac{\text { Ppeak }}{\text { Prated }}
$$

$\mathrm{U}_{\mathrm{f}} \quad$ : faktor penggunaan

$\mathrm{P}_{\text {peak }} \quad$ : beban puncak (MW)

$\mathrm{P}_{\text {rated }} \quad$ : kapasitas sistem (MW)

Jika nilai Uf sebuah trafo daya melebihi nilai standar yang telah ditetapkan, dibutuhkan tambahan piranti dengan besar kapasitas yang dapat dihitung menggunakan persamaan: [7].

$$
P_{\text {new }}=P_{\text {peak } X} L F-P_{\text {cap } X} U_{f}
$$

dengan :

$\mathrm{P}_{\text {new }} \quad$ : Kapasitas tambahan (MVA)

$P_{\text {peak }} \quad$ : Beban puncak (MVA)

$L F \quad$ : Faktor beban (\%)

$\mathrm{P}_{\text {cap }} \quad$ : Kapasitas trafo existing (MVA)

$\mathrm{U}_{\mathrm{f}} \quad$ : Faktor penggunaan standar (\%)

\section{Beban Harian}

Kurva beban harian seperti pada Gambar 2. menunjukkan besar konsumsi listrik selama satu hari (24 jam). Dari kurva beban dapat dilihat bahwa beban puncak terjadi pada pukul 18:00 WIB. Beban puncak adalah beban maksimum pada periode waktu tertentu, dan terjadi dengan durasi yang singkat.

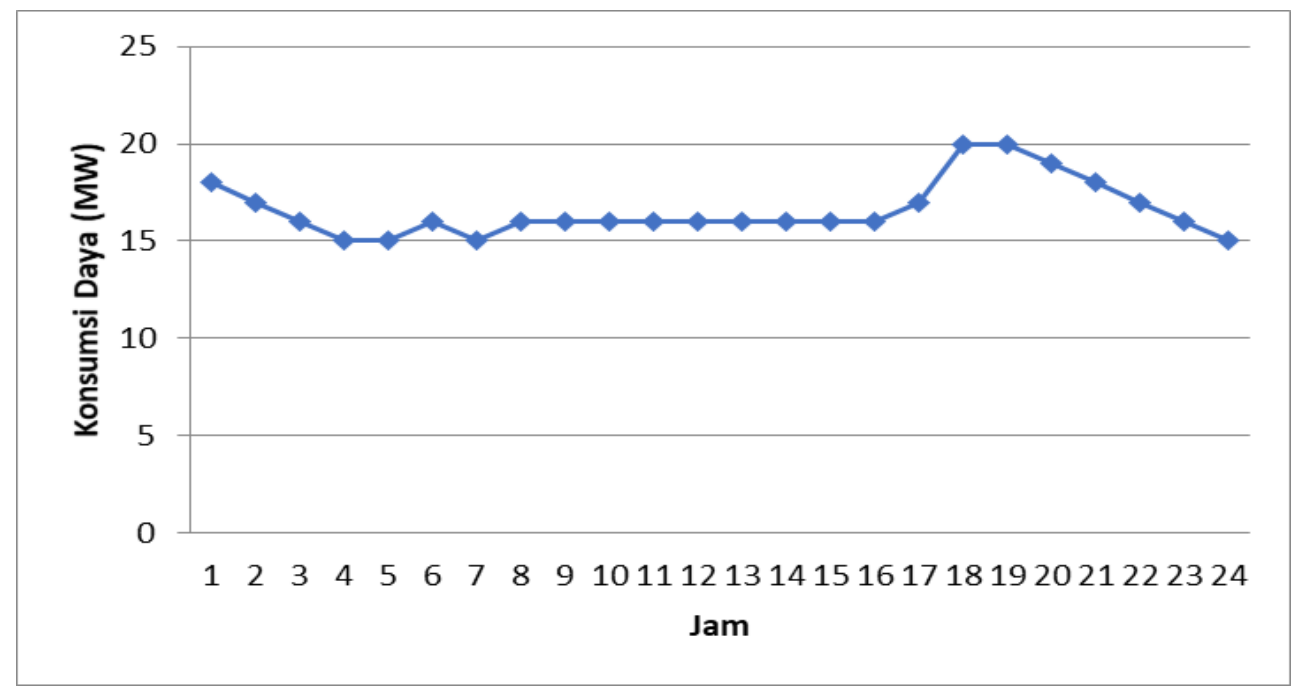

Gbr 2. Kurva Beban Harian

\section{E. Diagram Alir Penelitian}

Diagram alir (flowchart) penelitian dijabarkan pada Gambar 3. Dalam pengumpulan data pada penelitian ini, data yang diambil yang terkait dengan judul penelitian seperti data beban puncak tiga penyulang yaitu Sine, Trinil dan Walikukun yang digunakan dalam peramalan beban diperoleh dari statik perusahaan PLN UP3 Madiun dari bulan Mei-Desember tahun 2018 dan data wilayah daerah distribusi GI Mantingan yaitu Widodaren, Mantingan, Karanganyar, Ngrambe dan Sine serta aliran daya per daerah tersebut yang digunakan sebagai pemetaan kerapatan beban perwilayah. Pengolahan data dalam penelitian ini dilakukan dengan melakukan pengolahan data dengan software-microsoft excel.

\section{F. Pemetaan Kerapatan Beban}

Dalam perencanaan Gardu Induk diperlukan pemetaan beban per satuan area agar nantinya dapat digunakan sebagai penghitungan lokasi optimal pembangunan GI. Kerapatan beban memberikan informasi besar beban di setiap area dengan luas tertentu, permasalahannya adalah data 
tersebut tidak dimiliki oleh PT PLN (Persero) UP3 Madiun. Perhitungan kerapatan beban dilakukan dengan menggunakan data beban dan data geografis seperti yang terlihat pada Gambar 4.

Untuk menghitung kerapatan beban di wilayah 5 kecamatan yaitu Ngrambe, Widodaren, Sine, Mantingan dan Karanganyar dilakukan beberapa tahapan seperti yang terlihat pada Gambar 4.

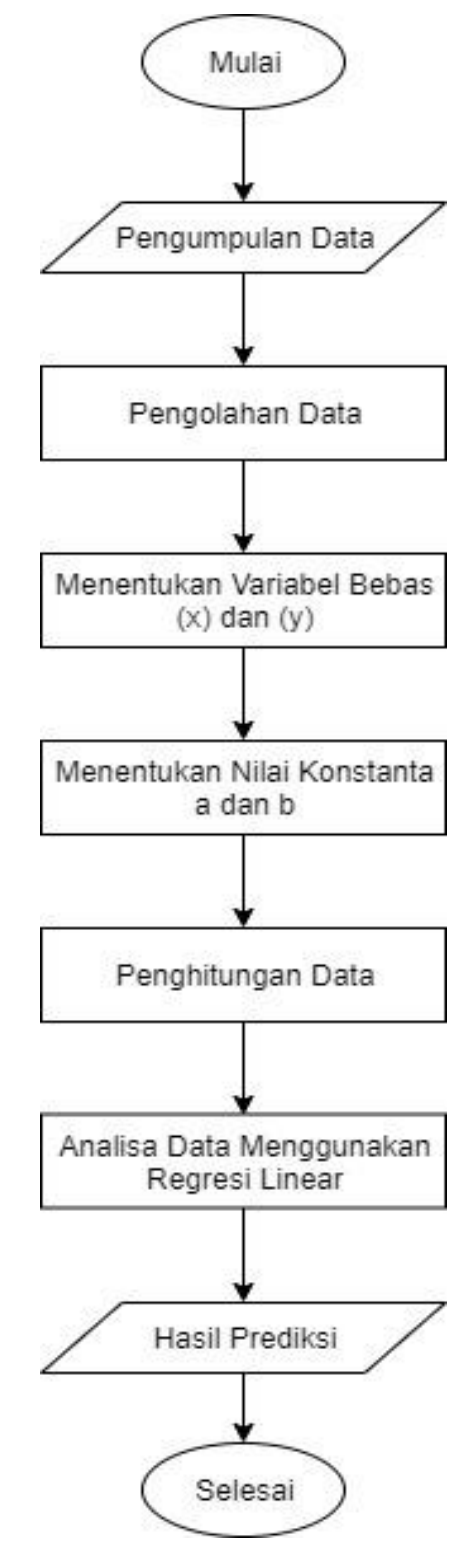

Gbr 3. Diagram Alir Penelitian

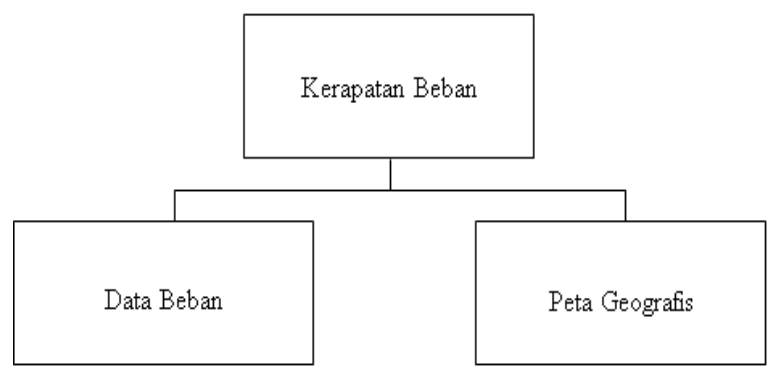

Gbr 4. Data Perhitungan Kerapatan Beban

Gambar 4 menunjukkan diagram alir proses penghitungan kerapatan beban. Pertama data geografis wilayah Ngrambe, Widodaren, Sine, Mantingan dan Karanganyar, yang berupa polygon diperoleh dari google mymaps dalam bentuk file dengan ekstensi .kmz ditunjukkan pada Gambar 5.

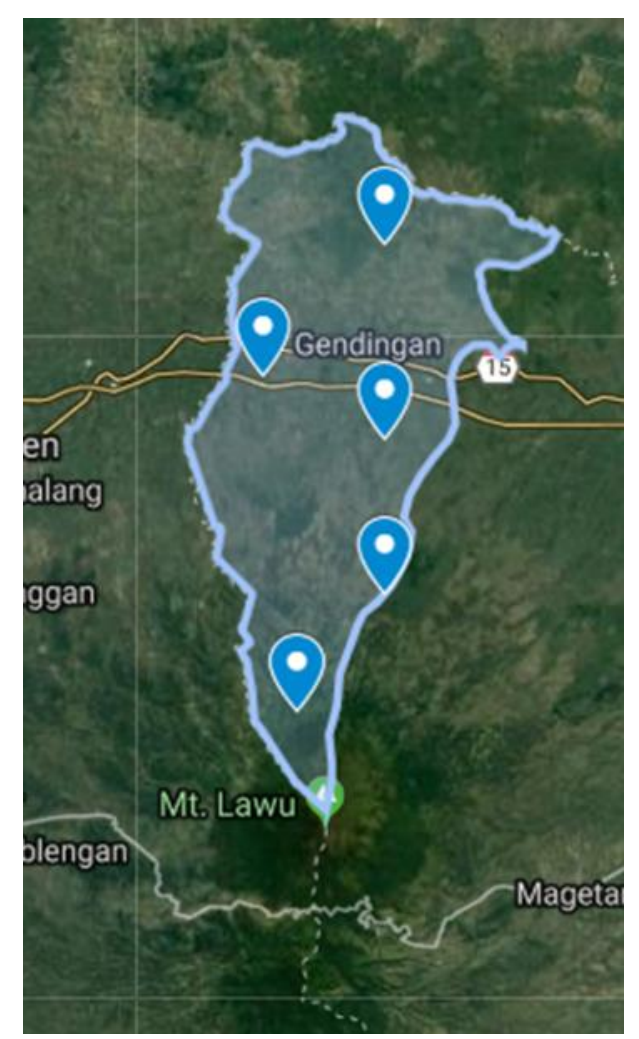

Gambar 5. Polygon dari Google My Maps

Untuk mengetahui besar kerapatan beban per kecamatan perlu diketahui besar konsumsi beban per kecamatan. Ada beberapa kecamatan yang disuplai oleh lebih dari satu penyulang. Pada Tabel 2, dapat dilihat persentasi kebutuhan kecamatan terhadap sebuah penyulang. Data aliran daya pada Tabel 2. adalah data yang diambil pada bulan Oktober 2018. 
Tabel 2. Aliran daya dan layanan penyulang

\begin{tabular}{|c|c|c|c|}
\hline \multirow{2}{*}{ Penyulang } & \multirow{2}{*}{$\begin{array}{c}\text { Aliran } \\
\text { Daya } \\
\text { (MVA) }\end{array}$} & $\begin{array}{c}\text { Area } \\
\text { Layanan }\end{array}$ & $\begin{array}{c}\text { Presentasi } \\
\text { konsumsi } \\
\text { daya per } \\
\text { penyulang } \\
\text { Sine }\end{array}$ \\
\cline { 3 - 4 } & \multirow{2}{*}{4,3} & Ngrambe & 34 \\
\cline { 3 - 4 } & & Widodaren & 21 \\
\cline { 3 - 4 } Trinil & \multirow{2}{*}{4,34} & Sine & 39 \\
\cline { 3 - 4 } & & Mantingan & 6 \\
\hline \multirow{2}{*}{ Walikukun } & \multirow{2}{*}{4,74} & Widodaren & 90 \\
\cline { 3 - 4 } & & Widodaren & 37 \\
\hline
\end{tabular}

Dengan data pada Tabel 2. besar kerapatan beban $\left(\mathrm{kw} / \mathrm{km}^{2}\right)$ per wilayah kecamatan dapat dicari, kemudian setelah itu kerapatan beban untuk per unit blok dapat ditentukan. Besar kerapatan beban unit blok di sebuah kecamatan belum tentu sama dengan besar kerapatan beban di kecamatan tersebut. Karena sebenarnya kerapatan beban di sebuah kecamatan berbeda-beda, oleh sebab itu di tahap selanjutnya hasil kerapatan beban di bandingkan dengan peta administrasi dan hasil pencitraaan dengan google maps.

Dalam penelitian ini, besar kerapatan beban yang digunakan bukan merupakan nilai hasil perhitungan. Setiap blok beban akan memiliki besar kerapatan beban yang digolongkan sesuai dengan Tabel 3.

Tabel 3. Penggolongan kerapatan beban

\begin{tabular}{|c|l|c|c|c|}
\hline $\begin{array}{c}\text { Indeks } \\
\text { kerapatan } \\
\text { beban }\end{array}$ & \multicolumn{1}{|c|}{ Deskripsi } & $\begin{array}{c}\text { Representasi } \\
\text { warna }\end{array}$ & $\begin{array}{c}\text { Rentang } \\
\text { kerapatan } \\
\text { beban per } \\
\text { wilayah } \\
(\mathbf{k V A} / \mathbf{k m})\end{array}$ & $\begin{array}{c}\text { Besar } \\
\text { kerapatan } \\
\text { beban } \\
(\mathbf{k V A} / \mathbf{k m})\end{array}$ \\
\hline H1 & Kerapatan beban tinggi & Merah & $91-160$ & 120 \\
\hline H2 & Kerapatan beban sedang & Ungu & $71-90$ & 80 \\
\hline H3 & Kerapatan beban rendah & Kuning & $26-70$ & 55 \\
\hline H4 & Kerapatan beban sangat rendah & Hijau & $0-25$ & 20 \\
\hline
\end{tabular}

\section{G. Kekangan}

a. Kekangan jatuh tegangan

Terdapat jarak maksimum antara GI dengan beban. Semakin jauh jarak GI terhadap beban maka akan semakin besar jatuh tegangan yang terjadi. PLN memiliki standar batas tegangan layanan maksimum dan minimum, untuk tegangan $20 \mathrm{kV}$, batas tegangan maksimum adalah 5\% diatas tegangan normal, yaitu $21 \mathrm{kV}$, sedangkan batas tegangan minimum adalah $10 \%$ dibawah tegangan normal, yaitu $18 \mathrm{kV}$. (Grid Code Java-Bali System, PLN).

Besar momen listrik untuk saluran udara dengan penghantar AAAC dan kondisi jatuh tegangan sebesar $1 \%$ ditunjukkan pada Tabel 4.
Tabel 4. Momen listrik jaringan distribusi AAAC, M1\% [MW.km]

\begin{tabular}{|c|c|c|c|c|c|}
\hline \multirow{2}{*}{$\begin{array}{c}\text { Penampang } \\
\left(\mathbf{m m}^{2}\right)\end{array}$} & \multicolumn{5}{|c|}{ Cos phi } \\
\cline { 2 - 6 } & $\mathbf{1}$ & $\mathbf{0 , 9 5}$ & $\mathbf{0 , 9}$ & $\mathbf{0 , 8 5}$ & $\mathbf{0 , 8}$ \\
\hline 35 & 4 & 3,6 & 3,4 & 4,3 & 3,2 \\
\hline 70 & 7,7 & 6,3 & 5,8 & 5,4 & 4,6 \\
\hline 150 & 12,1 & 11,5 & 10 & 8,9 & 8 \\
\hline 240 & 16,77 & 15 & 12,5 & 10,9 & 9,7 \\
\hline
\end{tabular}

b. Kapasitas GI

Batas pembebanan dari GI tidak boleh melebihi kapasitas maksimumnya. Berdasarkan RUPTL PLN 2015-2024, kapasitas GI maksimum sebelum perlu dilakukannya perencanaan STL adalah 70$80 \%$ dari nilai rating.

Pembebanan pada trafo di GI dihitung menggunakan beban puncak tahunan. Beban 
puncak tahunan adalah beban maksimum yang tercatat dalam periode 1 tahun.

\section{HASIL DAN PEMBAHASAN}

\section{A. Peramalan Beban}

Untuk melaksanakan perencanaan pembangunan GI jangka panjang, dibutuhkan proyeksi beban 8 tahun mendatang, hal tersebut diperoleh dari hasil peramalan menggunakan beban di masa lalu dari ketiga penyulang yaitu Walikukun, Sine dan Trinil. Adapun besar beban puncak 3 penyulang bulan tahun 2011 sampai dengan 2018 dapat dilihat pada Tabel 5.

Tabel 5. Beban Puncak 3 Penyulang bulan MeiDesember tahun 2018

\begin{tabular}{|c|c|c|c|c|}
\hline \multirow[b]{2}{*}{ Tahun } & \multicolumn{3}{|c|}{ Beban Puncak } & \multirow{2}{*}{$\begin{array}{c}\text { Beban } \\
\text { Total } 3 \\
\text { Penyulang }\end{array}$} \\
\hline & Sine & Trinil & $\begin{array}{c}\text { Wali } \\
\text { kukun }\end{array}$ & \\
\hline 2011 & 215 & 217 & 237 & 13,38 \\
\hline 2012 & 199 & 198 & 215 & 12,24 \\
\hline 2013 & 191 & 148 & 194 & 10,66 \\
\hline 2014 & 190 & 150 & 193 & 10,66 \\
\hline 2015 & 203 & 200 & 217 & 12,4 \\
\hline 2016 & 221 & 213 & 230 & 13,28 \\
\hline 2017 & 271 & 217 & 237 & 14,5 \\
\hline 2018 & 207 & 207 & 240 & 13,08 \\
\hline
\end{tabular}

Dari rekapitulasi data beban puncak 3 penyulang yang diperoleh dari statik perusahaan PLN UP3 Madiun dari bulan tahun 2011 sampai dengan 2018 dengan melakukan perhitungan data seperti pada Tabel 6.

Tabel 6. Konstanta a dan Koefisien b

\begin{tabular}{|c|c|c|c|c|}
\hline Tahun & $\begin{array}{c}\text { Variab } \\
\text { el x : } \\
\text { Periode } \\
\text { Bulan }\end{array}$ & $\begin{array}{c}\text { Variabel } \\
\mathbf{y}: \\
\text { Beban } \\
\text { Puncak 3 } \\
\text { Penyula } \\
\text { ng }\end{array}$ & $\mathbf{x}^{\mathbf{2}}$ & $\mathbf{x . y}$ \\
\hline 2011 & 1 & 13,38 & 1 & 13,38 \\
\hline 2012 & 2 & 12,24 & 4 & 24,48 \\
\hline 2013 & 3 & 10,66 & 9 & 31,98 \\
\hline 2014 & 4 & 10,66 & 16 & 42,64 \\
\hline 2015 & 5 & 12,4 & 25 & 62 \\
\hline 2016 & 6 & 13,28 & 36 & 79,68 \\
\hline 2017 & 7 & 14,5 & 49 & 101,5 \\
\hline
\end{tabular}

\begin{tabular}{|c|c|c|c|c|}
2018 & 8 & 13,08 & 64 & $\begin{array}{c}104,6 \\
4\end{array}$ \\
\hline TOTAL & 36 & 100,2 & 204 & 460,3 \\
\hline
\end{tabular}

Nilai konstanta (a) dan koefisien regresi $(b)$ sebagai berikut:

$$
\begin{aligned}
& \mathrm{a}=\frac{\left(\sum y\right)\left(\sum x^{2}\right)-\left(\sum x\right)\left(\sum x y\right)}{n\left(\sum x^{2}\right)-\left(\sum x\right)^{2}} \\
& \mathrm{a}=\frac{(100,2)(204)-(36)(460,3)}{8(204)-(36)^{2}} \\
& \mathrm{a}=\frac{(20.440,8)-(16.570,8)}{1632-1296} \\
& \mathrm{a}=\frac{3.870}{336} \\
& \mathrm{a}=11,51
\end{aligned}
$$

$\mathrm{b}=\frac{n\left(\sum x y\right)-\left(\sum x\right)\left(\sum y\right)}{n\left(\sum x^{2}\right)-\left(\sum x\right)^{2}}$

$\mathrm{b}=\frac{8(460,3)-(36)(100,2)}{8(204)-(36)^{2}}$

$\mathrm{b}=\frac{(3682,4)-(3607,2)}{1632-1296}$

$\mathrm{b}=\frac{75,2}{336}$

$\mathrm{b}=0,2238$

sehingga variabel dependent diprediksi dengan ramalam beban selama periode 8 tahun (tahun 2019 - 2026) ditentukan:

$$
\begin{aligned}
& \mathrm{y}=11,51+0,2238(13)=14,42 \mathrm{MVA} \\
& \mathrm{y}=11,51+0,2238(25)=17,10 \mathrm{MVA} \\
& \mathrm{y}=11,51+0,2238(37)=19,79 \mathrm{MVA} \\
& \mathrm{y}=11,51+0,2238(49)=22,57 \mathrm{MVA} \\
& \mathrm{y}=11,51+0,2238(61)=25,16 \mathrm{MVA} \\
& \mathrm{y}=11,51+0,2238(73)=27,84 \mathrm{MVA} \\
& \mathrm{y}=11,51+0,2238(85)=30,53 \mathrm{MVA} \\
& \mathrm{y}=11,51+0,2238(97)=33,21 \mathrm{MVA}
\end{aligned}
$$

Sedangkan untuk hasil prediksi ramalan beban 3 penyulang gardu induk Mantingan tahun 2019 sampai dengan tahun 2026 dapat dilihat pada Tabel 7. 
Tabel 7. Hasil Prediksi Ramalan Beban 3

Penyulang GI Mantingan

\begin{tabular}{|c|c|}
\hline Tahun & $\begin{array}{c}\text { Beban Puncak } \\
\text { (MVA) }\end{array}$ \\
\hline 2019 & 14,41 \\
\hline 2020 & 17,10 \\
\hline 2021 & 19,79 \\
\hline 2022 & 22,47 \\
\hline 2023 & 25,16 \\
\hline 2024 & 27,85 \\
\hline 2025 & 30,53 \\
\hline 2026 & 33,21 \\
\hline
\end{tabular}

Untuk pemilihan kapasitas trafo digunakan 2 permisalan apabila menggunakan kapasitas trafo 30 MVA dan 60 MVA.

$$
\begin{aligned}
\mathrm{Uf} & =33,21 \mathrm{MVA} / 30 \mathrm{MVA} \\
& =110,7 \%
\end{aligned}
$$

\section{Dengan Kapasitas Trafo 60 MVA \\ Uf $=33,21 \mathrm{MVA} / 60 \mathrm{MVA}$

$$
=72,29 \%
$$

Berdasarkan besar nilai $U_{f}$ yang telah dihitung, maka kapasitas trafo yang digunakan agar dapat memenuhi beban puncak sampai tahun 2026 yaitu trafo berkapasitas 60 MVA karena nilai tersebut lebih kurang dari dari $\mathrm{U}_{\mathrm{f}}$ standar PLN yaitu $80 \%$. Pertumbuhan beban dan kapasitas beban pada gardu induk Mantingan dapat ditunjukkan pada Gambar 6.

\section{Dengan Kapasitas Trafo 30 MVA}

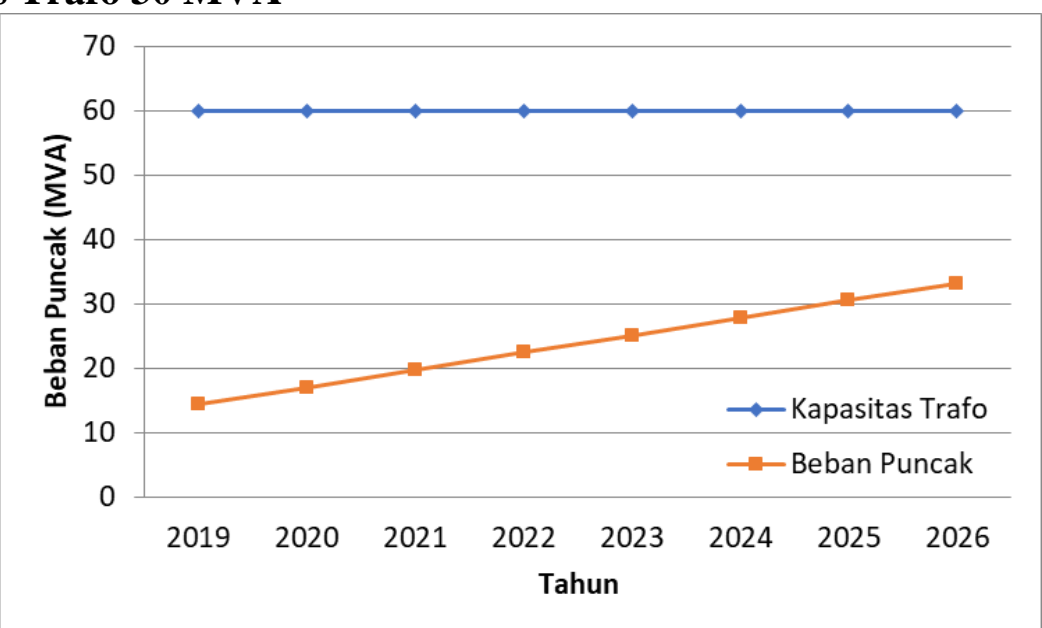

Gbr 6. Pertumbuhan beban dan kapasitas GI Mantingan

\section{B. Kapasitas GI yang perlu Dibangun}

Berdasarkan hasil peramalan yang telah dilakukan untuk tahun 2026 didapatkan beban puncak 33,21 MVA. Pada umumnya PLN menggunakan trafo dengan kapasitas 16, 30, 60, atau 100 MVA pada GI 150/20 kV. Sesuai dengan perhitungan yang telah dilakukan, agar GI mampu melayani beban sampai tahun 2026 dengan harapan pada tahun 2026 faktor pembebanan trafo (Uf) lebih kecil dari $80 \%$. Maka sesuai standar trafo PLN, wilayah Mantingan memerlukan GI dengan total kapasitas trafo 60 MVA. Yaitu dengan satu buah trafo berukuran 60 MVA untuk satu GI Mantingan.

\section{BPP Rata-rata}

Berdasarkan statistik PLN 2013[8], biaya produksi listrik dari tahun 2012-2018 adalah seperti pada Tabel 8. Dari Tabel 8 dapat terlihat biaya pokok penyediaan listrik (BPP) $(\lambda)$ meningkat setiap tahunnya karena dipengaruhi oleh inflasi dan faktor lain. Oleh sebab itu nilai yang digunakan untuk fungsi tujuan adalah BPP rata-rata 8 tahun ke depan.

Tabel 8. BPP PLN tahun 2012-2018

\begin{tabular}{|c|c|}
\hline Tahun & BPP (Rupiah) \\
\hline 2012 & 1341 \\
\hline 2013 & 1380 \\
\hline 2014 & 1420 \\
\hline 2015 & 1540 \\
\hline 2016 & 1617 \\
\hline 2017 & 1693 \\
\hline 2018 & 1769 \\
\hline
\end{tabular}


Hasil ramalan BPP untuk 8 tahun ke depan dapat dilihat pada Tabel 9. Dari hasil perhitungan BPP tersebut, dihitung nilai ratarata, yang hasilnya adalah $\mathrm{BPP}(\boldsymbol{\lambda})$ rata-rata $=$ Rp. 2.101,-.

Tabel 9. Hasil ramalan BPP PLN tahun 2019 - 2026

\begin{tabular}{|c|c|}
\hline Tahun & $\begin{array}{c}\text { BPP } \\
(\mathbf{R p})\end{array}$ \\
\hline 2019 & $1.838,-$ \\
\hline 2020 & $1.913,-$ \\
\hline 2021 & $1.988,-$ \\
\hline 2022 & $2.063,-$ \\
\hline 2023 & $2.139,-$ \\
\hline 2024 & $2.214,--$ \\
\hline 2025 & $2.289,-$ \\
\hline 2026 & $2.364,--$ \\
\hline
\end{tabular}

\section{Pembebanan Transformator}

Besar pembebanan trafo $\left(\mathrm{U}_{\mathrm{f}}\right)$ pada unit trafo yang baru dipengaruhi oleh pembebanan di masing-masing penyulang. Hasil pembagian beban dapat dilihat pada Tabel 10. Sehingga, dapat ditentukan pembebanan rata-rata selama 8 tahun sebesar $41,41 \%$.

Tabel 10. Strategi pembebanan GI

\begin{tabular}{|c|c|c|}
\hline Tahun & $\begin{array}{c}\text { Beban Puncak } \\
\text { (MVA) }\end{array}$ & $\mathbf{U}_{\mathbf{f}}$ GI (\%) \\
\hline 2019 & 14,41 & 31,33 \\
\hline 2020 & 17,1 & 37,17 \\
\hline 2021 & 19,79 & 43,02 \\
\hline 2022 & 22,47 & 48,85 \\
\hline 2023 & 25,16 & 54,70 \\
\hline 2024 & 27,85 & 60,54 \\
\hline 2025 & 30,53 & 66,37 \\
\hline 2026 & 33,21 & 72,20 \\
\hline \multicolumn{2}{|r|}{ IV. } & KESIMPULAN \\
\hline
\end{tabular}

1. Prediksi total kenaikan jumlah beban puncak 3 penyulang yaitu sine, trinil dan walikukun adalah sebesar 18,8 MVA dari tahun 2019 (rata-rata pertumbuhan per tahun sebesar 18,66\%).

2. Kapasitas GI yang digunakan agar dapat melayani beban selama 8 tahun kedepan adalah 60 MVA. Hal ini ditetapkan berdasarkan perhitungan ramalan beban puncak 8 tahun mendatang yaitu pada tahun 2026 sebesar 33,21 MVA.

3. Dalam perhitungan nilai $\mathrm{U}_{\mathrm{f}}$ (faktor pemakaian) dengan 2 permisalan trafo yaitu 30 dan 60 MVA. Maka dengan trafo berukuran 60 MVA didapatkan nilai $\mathrm{U}_{\mathrm{f}}$ sebesar 72,29\%. Hal ini sesuai dengan standar peralatan GI PLN yaitu $\mathrm{U}_{\mathrm{f}}$ dibawah $80 \%$.

4. Besar biaya pokok penyediaan listrik untuk 8 tahun kedepan berdasarkan perhitungan menggunakan regresi linear adalah BPP $(\boldsymbol{\lambda})$ rata-rata $=\mathrm{Rp} .2 .101$. Sedangkan besar nilai pembebanan trafo GI Mantingan selama 8 tahun memiliki rata-rata sebesar $41,41 \%$.

\section{REFERENSI}

[1] M. S. Seifi, Hossein, Sepasian, Electrical Power System Planning. Berlin: SpringerVerlag, 2011.

[2] Cebeci, M. E., Eren, S., Tor, O. B., \& Güven, N. (2011). Transmission and Substation Expansion Planning using Mixed Integer Programming. North American Power Symposium, 1-5.

[3] Poston, J. D., \& Bouvier, L. F. (2010). An Introduction to Demography. Cambridge: Cambridge University Press.

[4] Ebrahimporain, R., \& Kazemi, M. (2014). Multi-Objective Placement of Multiple Distributed Energy Resources in Distribution System Using Imperialist Competitive Algorithm (ICA). International Journal on Technical and Physical Problems of Engineering (IJTPE), 6 (18), 89-95.

[5] Singh, R. P. (2011). Singh, R. P. (2011). Heritagescapes \& Cultural Landscapes: An Appraisal. Planet Earth \& Cultural Understanding Series, 7.

[6] Ravadanegh, S. N., \& Roshanagh, R. G. (2013). A Heuristic Algorithm for Optimal Multistage Sizing, Siting and Timing of MV Distribution $\mathrm{S}$ ubstations. Electric Power Systems Research 105, 134-141.

[7] Roshanagh, S. N., \& Ravadanegh, R. G. (2014). On Optimal Multistage Electric Power Distribution Networks Expansion Planning. Electrical Power and Energy Systems 54, 487-497. 